\title{
Modelling of Harmonic Response of Scarf Adhesive Joints
}

\author{
Awad A. Alqahtani, Khalid H. Almitani, and Ramzi Othman
}

\begin{abstract}
Adhesives are used for attaching structures to various spacers such as tubular and scarf joints to replace the traditional joining methods of welding, brazing, soldering, etc. Many of the unique features associated with adhesives are low manufacturing cost, long component life, and lightweight. Accordingly, a considerable amount of study has been carried out and is still underway to develop. The main objective of this study is to investigate the response of the scarf joints when exposed to a harmonic load. The finite element method (FEM) using ANSYS is availed to study and analysis the natural frequencies, mode shape, and frequency response. Additionally, the influence of the adhesion angle is examined.
\end{abstract}

Index Terms - Adherends; Ansys; Finite Element Modelling (FEM), Scarf Adhesive Joints.

\section{INTRODUCTION}

Scarf joints involve complex deformation states especially when using the traditional attachment techniques [1]. As a result, the use of adhesives in the joining of scarf structures has been steadily increasing [2], [3]. This use of adhesives comes amidst the urge to replace these old methods, such as brazing, welding, and soldering. The utilization of adhesives has been found to reduce the production cost, as well as to make components' life longer by decreasing the response to vibrations.

The characteristics of these adhesive materials are remarkable. As a result, these significant weaknesses led to the need to produce better adhesives and appropriate surface processing equipment to make adhesive surfaces effective [4], [5]. Also, scarf joints are believed to have defects, such as gaps, voids, ineffective surface, and curing, which may affect the quality of the bond, as well as both dynamic, and static responses [16].

With all these advantages, the application of adhesives is often used with cautious especially that concerned with longterm impact, when subjected to various environmental conditions [6]. Due to the need to study the dynamic response and behavior of the scarf adhesive joint under a harmonic load, this study comes to understand and analyze that.

At the beginning of the 20th century, the technological creation of an adhesive joint started with Volkersen's work [28], and several others followed, such as Charalambides [29], Goland [30], and others. The adhesively bonded joints currently play an important role in the industry and civil engineering, as they achieve resistant and robust joints [13]. Because of the ease of production and the lack of any technical expertise in the development process, the single-lap joint is also the most commonly used one.
The geometry is straightforward, but the stress distributions are very complex. Double lap joints, step joints, and scarf joints are among other common joint arrangements. Scarf joints, however, can be found highly fascinating because they do not induce adhesion bending, which adversely influences the strength of the joint, unlike singlelap joints [1]. Thanks to their ability to assemble a wide variety of components, adhesive joints seem to be an interesting tool for minimizing the weight and expense of structures in diverse manufacturing fields. However, adhesives are significantly underused because of the lack of faith in non-destructive quality assessment. The need to suggest testing to assess the durability of assembly choices that can be used for the construction of adhesively bonded structures is another important point. The experimental characterization of the potential assemblies is not a simple task because of the severe edge effects (linked with a geometrical and material mismatch between the adhesive and the substrates) and the complex failure dynamics that could be produced [2].

Due to a large amount of material and geometric variables affecting the efficiency of scarf repair, the design of the optimum scarf repair for a given application (especially for composite structures) is complicated. There are also different experiments to find exact design instruments for the static power of scarf joints or replacements because of this. They can be analytical, numerical, or experimental. The early work of Jones and Graves is an example of experimental experiments on scarf repairs [1].

The study of adhesive-bonded joints involves knowledge of the structural adhesive's stress-strain nature, and there are many test methods for this reason [15]. To promote this experimental characterization, some experiments have been normalized, such as the single-lap joint test. However, the estimation of a consistent intensity is not negligible because of the pressure concentrations at the ends of the overlap, Although, some studies suggest some solutions and ideas to reduce the edge effects. In addition, this test is dedicated to determining the strength of a given peel/shear stress ratio that is believed to be a quasi-pure shear, while high peel stresses are produced at the ends of the overlap, some studies suggest some modifications by subjecting the adhesive to variable combinations of peeling and shearing stresses [2].

During the treatment of surfaces, the efficiency of bonded CFRP joints has been enhanced by various methods. Mechanical, plasma, chemical, and laser surface applications can be loosely categorized into methods. Mechanical surface treatments, such as grit, grinding, or baking, improve 
ruggedness, reduce corrosion, and expose the new materials to a new layer [3]. Surface treatment with chemicals and plasma has been documented in order for usable groups to be taken to the surface. Plasma surface therapy may also be used to eliminate release agents. [3].

Khashaba [5,8] addresses the use of nanoparticles in functional applications such as laminated composites, adhesive joints, and hybrid joints as entirely new subjects, and enhancing the efficiency of the mantle joint in composite structures by using $\mathrm{Al}_{2} \mathrm{O}_{3}$ or $\mathrm{SiC}$ nanoparticles have not yet been studied, but there are some attempts on single-coil metal joints, so great attention should be paid to [5].

Andrea Dorigato and Alessandro Pegoretti [6], showed that the temperature of the glass transformation of the nano-filled adhesives increased to maximum filler filling and then decreased, possibly due to the parallel and opposing effects of blocking the chain and decreasing the degree of crosslinking. The presence of untreated alumina nanoparticles at an acceptable filler content has positively influenced the tensile modulus, split stress, and crack strength of the bulk adhesive [6].

Korayem et al. [18] found that the CNT-reinforced epoxy has Young's modulus 20\% higher than the neat epoxy. The reinforced epoxy has also a tensile strength $30 \%$ higher than the neat epoxy. However, the elongation-to-failure is reduced by about $41 \%$. Studying, analyzing, and simulating all these details has been difficult historically, but now the methodology of finite elements takes the lead in the analytical processes in this century. In only a few decades, this technology has evolved, from the first use of a large scale and richly different electronic solution for many science and technology fields in 1941 in aircraft structural analysis and structural engineering. Stress analysis is often complicated and for many engineering challenges in the field of structural mechanics; theoretical solutions are exceedingly difficult and repetitive [15]. Approximate and sufficient ways to solve most functional problems are found in numerical methods. With the introduction of computers, one of the best methods that emerged in the area of engineering research is the finite element approach and a general method for the study of structures that are solid in complex shapes and complicated bounds. FEM splits a structure into several elements (structure parts), then reconnects elements to "nodes" as if nodes were pins or drops of glue binding elements together, resulting in a sequence of algebraic equations concurrently [14].

It is possible to divide the current theoretical analyses on complex activities into two categories: finite element analysis (FEA) and empirical science. Through the advent of industrial FEA methods, modeling the bonded joint and simulating the joint's mechanical behaviors has become simpler [19].

Through studying the stress of an independent lap joint with FEM, Baylor and Sancaktar showed that, when a mesh density along the transverse path of an overlap reaches 3 elements per $\mathrm{mm}$, it will essentially eliminate the variation of maximal main stress and of mesh density in Misses. 25 elements per $\mathrm{mm}$ in the peel direction were also found to contribute to the decoupling of these stresses with mesh densities with an adhesive thickness of $0.2 \mathrm{~mm}$ [17].

\section{METHODOLOGY}

The finite element analysis was performed through several steps using ANSYS workbench. First, we have assigned the material properties to the adherents and adhesive. Afterward, the design geometry was produced with the use of bonded contact conditions applied between each layer of adherents and adhesives. Then meshing and modal analysis.

Next, we have also assigned the material that makes up each part, and the position and amount of force applied during the test. Finally, we need to select the results that will be processed. Here our goal is to obtain the first four natural frequencies, the mode shape, and the frequency response.

The study will be carried out on a rectangular geometric shape, with external dimensions (length $200 \mathrm{~mm}$, width 10 $\mathrm{mm}$, adhesive thickness $0.5 \mathrm{~mm}$ ), the center of the scarf joint is in the middle of the shape and the dimensions of the shape are changed in order to change the angle of contact. In table III, we can see the dimensions of all cases of the study. The dimensions are given in millimeters. The structure is clamped from one edge and free from the other.

During the study of the frequency response, there is a load of $1 \mathrm{~N}$ at a distance of $30 \mathrm{~mm}$ from the left edge of the body's as shown in Fig. 1. The frequency response will be taken as the displacement along the $\mathrm{Y}$-axis

In this work we considered that adherends are aluminum and adhesive part is epoxy, the mechanical properties of these materials in Table I.

TABLE I: MECHANICAL PROPERTIES OF MATERIALS

\begin{tabular}{cccc}
\hline \hline Material & $\mathrm{E}(\mathrm{Gpa})$ & $\rho(\mathrm{kg} / \mathrm{m} 3)$ & $v$ \\
\hline Aluminum & 70 & 2770 & 0.34 \\
Epoxy & 2 & 1800 & 0.4 \\
\hline \hline
\end{tabular}

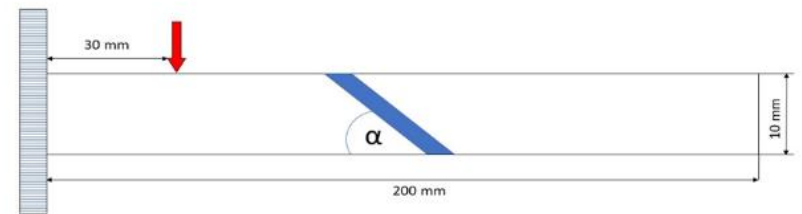

Fig. 1. 2D scarf joints with adhesive in the middle and shows the position of the force $30 \mathrm{~mm}$ from the beginning of the installation on.

The behavior of the natural frequency under this case will be studied by changing the angle of the scarf joint and the adhesive is always of constant thickness.

The finite element method (FEM) will be implemented using ANSYS to investigate the response of the scarf joints. For simplicity purposes, the numerical approach will be dealt considering the problem as a 2-D finite element model. Adherent and adhesive are assumed isotropic.

The accuracy that can be obtained from any FEA model is directly related to the finite element mesh that is used. As these elements are made smaller and smaller, the mesh is refined, and the computed solution will approach the true solution. The study of convergence requires the selection of an appropriate mesh refinement metric. Mesh element size is varied between 0.1 and $10 \mathrm{~mm}$. The convergence for a mesh size of $0.5 \mathrm{~mm}$. The process of mesh refinement is a key step in validating any finite element model and gaining confidence in the software, the model, and the results. 


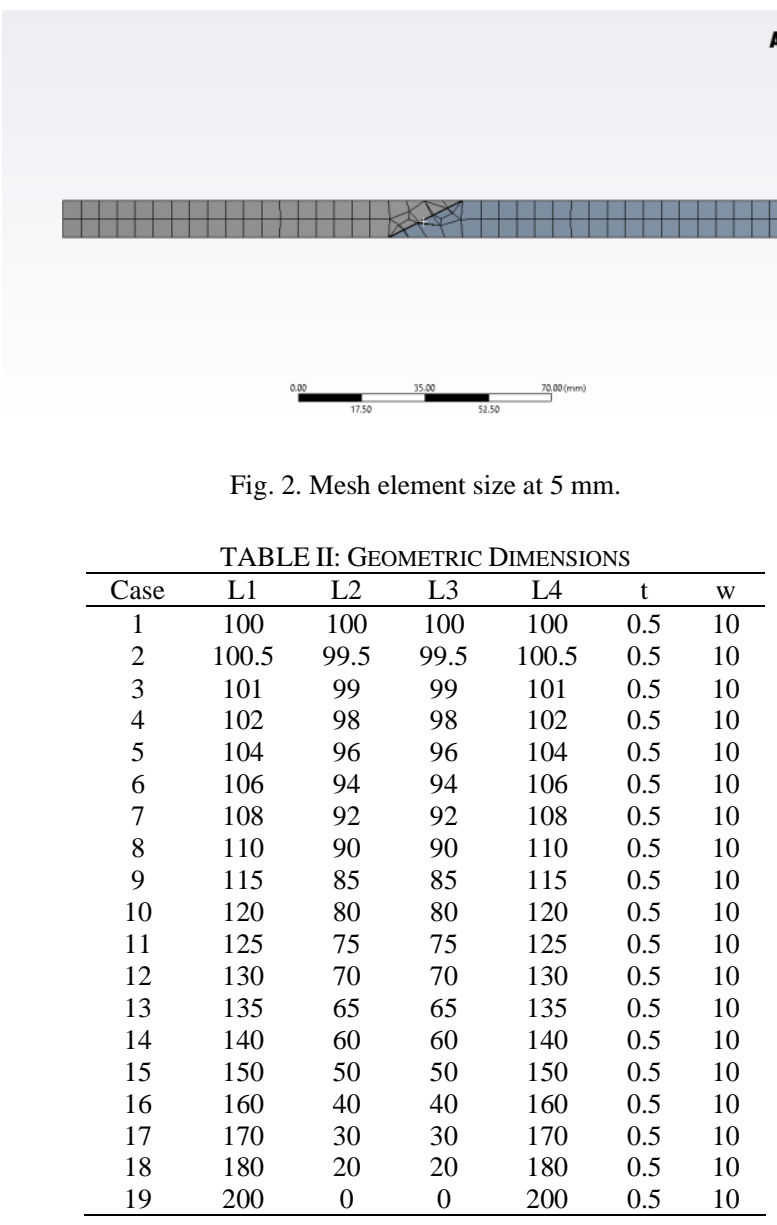

\section{RESULT AND DISCUSSION}

\section{A. Result}

The goal of this work is to obtain the first four natural frequencies, the mode shape, and the Frequency response of all cases shown in Table II.

For the (Clamped-Free) Aluminum scarf joint, we have studied the effect of scarf angle on the natural frequencies. From the Fig. 3, we can conclude that the natural frequencies are maximum at $90^{\circ}$ for all first four natural frequencies. However, the minimum is variable depending on the natural frequency. For the first natural frequency, the smallest value is reached at the angle $\left(2.83^{\circ}\right)$, while for the second natural frequency the smallest value is reached at $\left(18.43^{\circ}\right.$ and $\left.14.04^{\circ}\right)$, and for the third natural frequency, the lowest value is achieved at $\left(4.76^{\circ}\right)$. Finally, for the fourth natural frequency the smallest value is obtained at $3.57^{\circ}$ (see Table III and Fig. 3).

We can also notice that the difference between the maximum and minimum value of a normal frequency is not significant, $\mathrm{NF} 1=2.31 \mathrm{~Hz}, \mathrm{NF} 2=10.9 \mathrm{~Hz}, \mathrm{NF} 3=34.6 \mathrm{~Hz}$, and NF4 $=16.3 \mathrm{~Hz}$. The difference between the maximum and the minimum values is not significant and does not exceed $0.35 \%$ for all cases.

After studying the natural frequencies, we also studied the mode shapes (Fig. 4, 5, and 6). Through this study, it becomes clear that the effect of the angle of the mantle joint is very small. We compared the response of the presence of the scarf joint and a bulk aluminum beam. We found that the displacement was not significantly affected.
Three angles were chosen because results are close for all angles (Fig. 4, 5, and 6).

TABLE III: FirST Four NATURAL FREQUENCIES FOR EACH ANGLE

\begin{tabular}{|c|c|c|c|c|}
\hline \multirow{2}{*}{$\begin{array}{c}\text { Angle } \\
\text { (Degree) }\end{array}$} & \multicolumn{4}{|c|}{ Natural frequency $(\mathrm{Hz})$} \\
\hline & first & second & third & fourth \\
\hline $90^{\circ}$ & 220.62 & 1332.8 & 3670.9 & 6687.5 \\
\hline $84.29^{\circ}$ & 220.61 & 1332.6 & 3670.7 & 6687.3 \\
\hline $78.69^{\circ}$ & 220.57 & 1332.2 & 3670.2 & 6686.7 \\
\hline $68.2^{\circ}$ & 220.42 & 1330.5 & 3668.4 & 6684.6 \\
\hline $51.34^{\circ}$ & 220.09 & 1327.1 & 3663.8 & 6680.2 \\
\hline $39.8^{\circ}$ & 219.82 & 1324.5 & 3660.1 & 6677 \\
\hline $32^{\circ}$ & 219.65 & 1323 & 3657.5 & 6675.1 \\
\hline $26.56^{\circ}$ & 219.55 & 1322.2 & 3655.7 & 6673.9 \\
\hline $18.43^{\circ}$ & 219.42 & 1321.5 & 3652.3 & 6672.5 \\
\hline $14.04^{\circ}$ & 219.35 & 1321.5 & 3649.5 & 6671.9 \\
\hline $11.31^{\circ}$ & 219.31 & 1321.9 & 3646.8 & 6671.6 \\
\hline $9.46^{\circ}$ & 219.26 & 1322.4 & 3644.2 & 6671.4 \\
\hline $8.13^{\circ}$ & 219.21 & 1323 & 3641.7 & 6671.4 \\
\hline $7.125^{\circ}$ & 219.16 & 1323.7 & 3639.7 & 6671.3 \\
\hline $5.7^{\circ}$ & 219.05 & 1325.2 & 3636.9 & 6671.3 \\
\hline $4.76^{\circ}$ & 218.92 & 1326.6 & 3636.3 & 6671.2 \\
\hline $4.08^{\circ}$ & 218.77 & 1327.8 & 3637.3 & 6671.2 \\
\hline $3.57^{\circ}$ & 218.62 & 1328.6 & 3639 & 6671.2 \\
\hline $2.83^{\circ}$ & 218.31 & 1329 & 3640.2 & 6671.3 \\
\hline
\end{tabular}
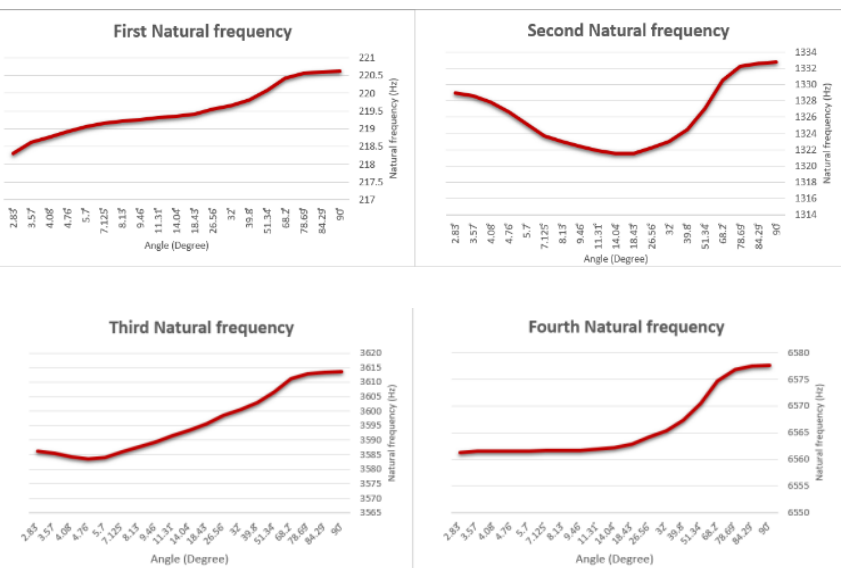

Fig. 3. First four natural frequencies of Aluminum with (C-F).

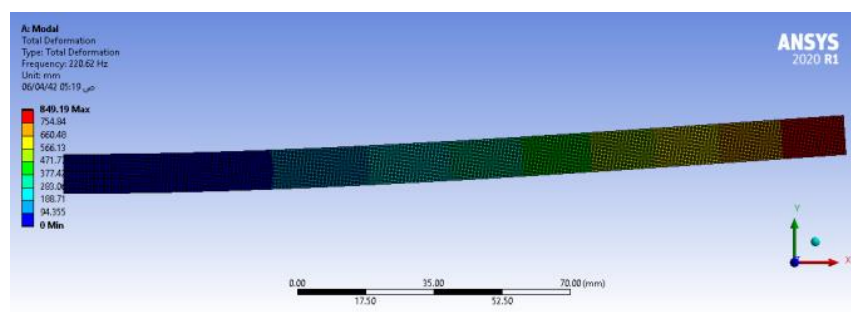

Fig. 4. Mode Shape of Aluminum with (C-F) At Angle $90^{\circ}$

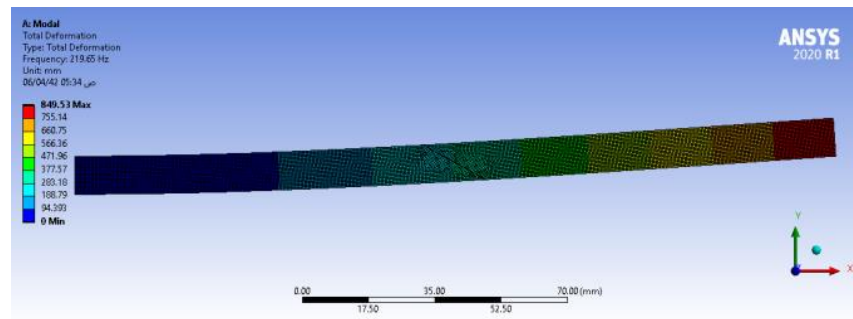

Fig. 5. Mode Shape of Aluminum with (C-F) At Angle $32^{\circ}$. 


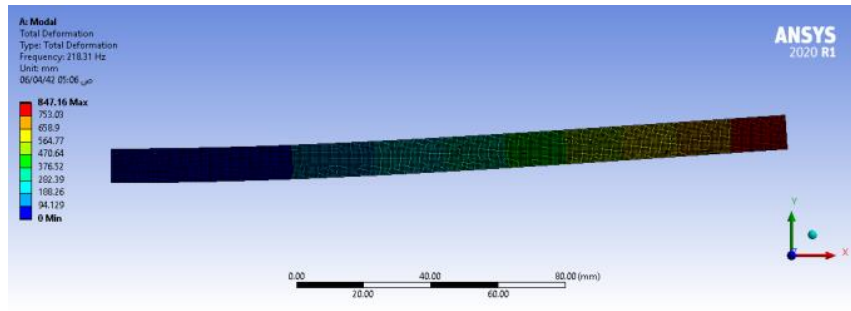

Fig. 6. Mode Shape of Aluminum with (C-F) At Angle $2.83^{\circ}$.

We have studied the frequency response of the (ClampedFree) Aluminum scarf joint for different angles and there is also no significant effect (Fig. 7).

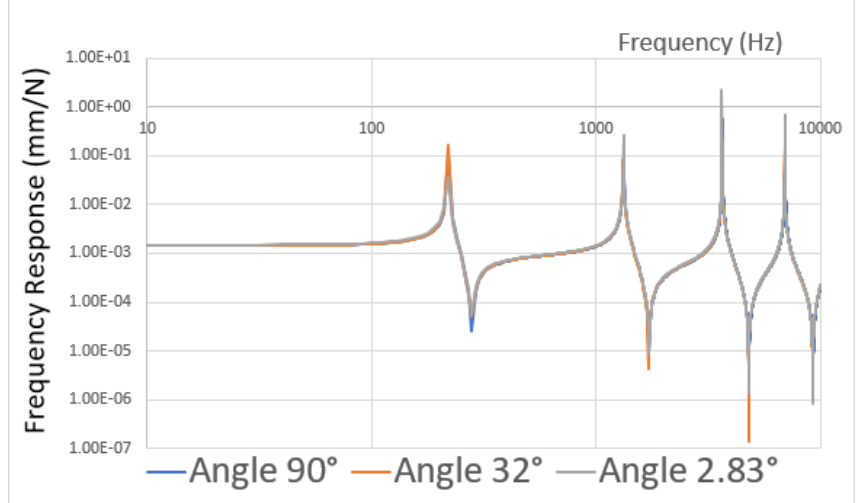

Fig. 7. Frequency Response of Aluminum (Clamped-Free).

\section{B. Discussion}

Now, the same geometric shape is tested by using aluminum and without the scarf joint, and the natural frequency is compared with and without the joint and the effect of that (Table IV).

TABLE IV: NATURAL FREQUENCIES WITH ONE BODY

\begin{tabular}{cc}
\hline \multicolumn{2}{c}{ Natural frequency $(\mathrm{Hz})$} \\
\hline first & 214.66 \\
second & 1328.3 \\
third & 3647.2 \\
fourth & 6676.2 \\
\hline
\end{tabular}

From Fig. 8. It is clear that the effect of the scarf joint on the first natural frequency is greater than the rest of the other three frequencies, at angle $90^{\circ}$ we notice that the effect is large, but it gradually decreases to be approximately one at $2.83^{\circ}$.

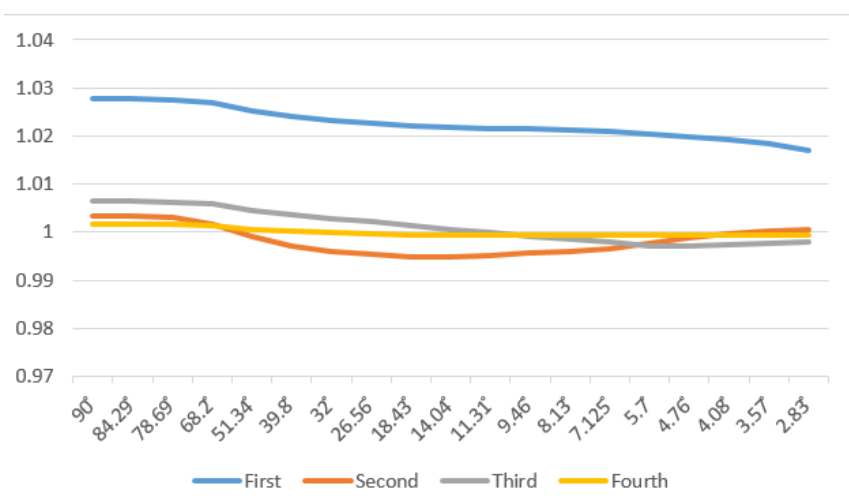

Fig. 8. The ratio of the impact of the scarf joint on the natural frequency.

\section{CONCLUSION}

Adhesives are increasingly for attaching structures to various spacers such as tubular and scarf joint to replace the traditional joining methods of welding, brazing, soldering, etc. Many of the unique features associated with adhesives are low manufacturing cost, long component life, and lightweight. Due to various applications of such components in huge industrial sectors such as aerospace and automotive industries, electrical and electronic industries, the development of joint performance will always be a call for attention in an integrated component. Accordingly, a considerable amount of study has been carried out and is still underway to develop.

The main objective is to investigate the response of the scarf joints when exposed to a harmonic load. The finite element method (FEM) using ANSYS is availed to study and analysis the natural frequencies, mode shapes, and frequency responses. The obtained results show that the effect of the scarf angle on the natural frequency is limited.

\section{REFERENCES}

[1] Alves, D. L., et al. "Experimental and numerical analysis of hybrid adhesively-bonded scarf joints." International Journal of Adhesion and Adhesives 83 (2018): 87-95.

[2] Carrere, Nicolas, et al. "3D models of specimens with a scarf joint to test the adhesive and cohesive multi-axial behavior of adhesives." International Journal of Adhesion and Adhesives 62 (2015): 154-164.

[3] Almitani, Khalid H., and Ramzi Othman. "Analytical solution of the harmonic response of visco-elastic adhesively bonded single-lap and double-lap joints." International Journal of Adhesion and Adhesives 71 (2016): 55-65.

[4] Harder, Sergej, et al. "Effect of infrared laser surface treatment on the morphology and adhesive properties of scarfed CFRP surfaces." Composites Part A: Applied Science and Manufacturing 121 (2019): 299-30.

[5] Khashaba, U. A., A. A. Aljinaidi, and M. A. Hamed. "Development of CFRE composite scarf adhesive joints with $\mathrm{SiC}$ and $\mathrm{Al} 2 \mathrm{O} 3$ nanoparticle." Composite Structures 128 (2015): 415-427.

[6] Dorigato, Andrea, and Alessandro Pegoretti. "The role of alumina nanoparticles in epoxy adhesives." Journal of Nanoparticle Research 13.6 (2011): 2429-2441.

[7] Zhai, Lanlan, et al. "The effect of nanoparticles on the adhesion of epoxy adhesive." Materials Letters 60.25-26 (2006): 3031-3033.

[8] Khashaba, U. A., A. A. Aljinaidi, and M. A. Hamed. "Fatigue and reliability analysis of nano-modified scarf adhesive joints in carbon fiber composites." Composites Part B: Engineering 120 (2017): 103 117.

[9] Riccio, A., et al. "Numerical investigation of constitutive material models on bonded joints in scarf repaired composite laminates." Engineering Fracture Mechanics 173 (2017): 91-106.

[10] Wang, Suian, Qi Guo, and Zonghong Xie. "Extended analytical model for interfacial stresses of double-lap joints under harmonic loads." International Journal of Adhesion and Adhesives 91 (2019): 23-35.

[11] Liao, Lijuan, Toshiyuki Sawa, and Chenguang Huang. "Experimental and FEM studies on mechanical properties of single-lap adhesive joint with dissimilar adherends subjected to impact tensile loadings." International Journal of Adhesion and Adhesives 44 (2013): 91-98.

[12] Sayegh, Ahmed Hasan, Khalid Almitani, and Ramzi Othman. "Numerical Analysis of Adhesive Joints with Bi-Layered Adherends." European Journal of Engineering and Technology Research 5.6 (2020): 731-735.

[13] Gacoin, A., et al. "Comparison between experimental and numerical study of the adhesively bonded scarf joint and double scarf joint: Influence of internal singularity created by geometry of the double scarf joint on the damage evolution." International journal of adhesion and adhesives 29.5 (2009): 572-579.

[14] Adin, Hamit. "The investigation of the effect of angle on the failure load and strength of scarf lap joints." International Journal of mechanical sciences 61.1 (2012): 24-31.

[15] Ting, T., et al. "Composite repairs to rib stiffened panels." Composite Structures 47.1-4 (1999): 737-743. 
[16] Aydin, Murat Demir, Adnan Özel, and Semsettin Temiz. "The effect of adherend thickness on the failure of adhesively-bonded single-lap joints." Journal of adhesion science and technology 19.8 (2005): $705-$ 718.

[17] Sancaktar, Erol, and Prasad Nirantar. "Increasing strength of single lap joints of metal adherends by taper minimization." Journal of adhesion science and technology 17.5 (2003): 655-675.

[18] Korayem, Asghar H., et al. "Failure of CFRP-to-steel double strap joint bonded using carbon nanotubes modified epoxy adhesive at moderately elevated temperatures." Composites Part B: Engineering 94 (2016): 95-101.

[19] Loos, M. R., et al. "Enhancement of fatigue life of polyurethane composites containing carbon nanotubes." Composites Part B: Engineering 44.1 (2013): 740-744.

[20] Khashaba, U. A., A. A. Aljinaidi, and M. A. Hamed. "Analysis of adhesively bonded CFRE composite scarf joints modified with MWCNTs." Composites Part A: Applied Science and Manufacturing 71 (2015): 59-71.

[21] Jen, Yi-Ming. "Fatigue life evaluation of adhesively bonded scarf joints." International journal of Fatigue 36.1 (2012): 30-39.

[22] Baldan, A. "Adhesion phenomena in bonded joints." International Journal of Adhesion and Adhesives 38 (2012): 95-116.

[23] Hayes-Griss, J. M., A. J. Gunnion, and A. Afaghi Khatibi. "Damage tolerance investigation of high-performance scarf joints with bondline flaws under various environmental, geometrical and support conditions." Composites Part A: Applied Science and Manufacturing 84 (2016): 246-255.

[24] Subramani, T., and Athulya Sugathan. "Finite element analysis of thin walled-shell structures by ANSYS and LS-DYNA." International Journal of Modern Engineering Research 2.4 (2012): 1576-1587.
[25] Breitzman, T. D, et al. "Optimization of a composite scarf repair patch under tensile loading." composites Part A: Applied science and manufacturing 40.12 (2009): 1921-1930.

[26] Gustafson, Peter A., and Anthony M. Waas. "The influence of adhesive constitutive parameters in cohesive zone finite element models of adhesively bonded joints." International Journal of Solids and Structures 46.10 (2009): 2201-2215.

[27] Erdogan, F., and M. Ratwani. "Stress distribution in bonded joints." Journal of Composite Materials 5.3 (1971): 378-393.

[28] Volkersen, Olaf. "Die Nietkraftverteilung in zugbeanspruchten Nietverbindungen mit konstanten Laschenquerschnitten." Luftfahrtfor schung 15 (1938): 41-47.

[29] Charalambides, M. N., A. J. Kinloch, and F. L. Matthews. "Adhesivelybonded repairs to fibre-composite materials II. Finite element modelling." Composites Part A: Applied Science and Manufacturing 29.11 (1998): 1383-1396.

[30] Goland, Ma. "The stresses in cemented joints." J. appl. Mech. 17 (1944): 66.

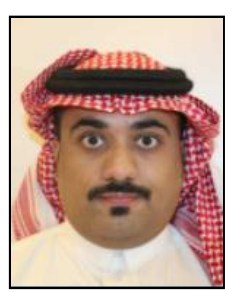

Awad A. Alqahtani

DOB: 1991, Abha Saudi Arabia.

Education: B.S. in Mechanical Engineering, King

Khaled University, Abha , KAS . 2015

(On going) M.S. in Mechanical Engineering, King

Abdulaziz University, Jeddah, Saudi Arabia. 